\title{
La enseñanza de la historia en un mundo globalizado
}

\author{
Guadalupe Gómez-Aguado*
}

\begin{abstract}
Resumen: Se ha dicho que en el contexto globalizado del siglo XXI las fronteras culturales tienden a desaparecer y las concepciones sobre el tiempo y la historia son iguales en todas partes. En ese sentido, en una realidad en la que el éxito económico se equipara con la felicidad y se busca la gratificación inmediata, la comprensión del pasado queda como una asignatura obsoleta que no tiene sentido en un mundo acostumbrado a la inmediatez.

Sin embargo, los seres humanos somos tiempo. El pasado está en nosotros, y nos explica y define. De ahí que la comprensión de la historia sea fundamental para entender, también, nuestra vida y los significados de la forma en que nos movemos y somos. El análisis de la época actual, en un contexto de globalización económica, así como los retos que implica la enseñanza de la historia hoy en día son el motivo de este artículo.
\end{abstract}

Palabras clave: historia, globalización, cultura, enseñanza, internet

INTRODUCCIÓN

El siglo XX, a decir de Eric Hobsbawm (2007: VII-X), fue "el periodo más extraordinario en la historia de la humanidad", ya que se sucedieron catástrofes humanas sin precedentes, impresionantes progresos materiales y un gran incremento en la capacidad del hombre para transformar y destruir la faz de la tierra. En ese sentido, la llamada globalización, especialmente en cuanto al mercado libre, trajo consigo el crecimiento de las desigualdades económicas y sociales en todos los países, lo que ha provocado tensiones sociales y políticas nunca antes vistas. Por otra parte, es un hecho que quienes sufren con mayor intensidad el impacto de la globalización son quienes menos se benefician de ella.

* Maestra en Historia moderna y contemporánea por el Instituto Mora. Profesora-investigadora de tiempo completo en el Centro de Enseñanza para Extranjeros de la UNAM adscrita al departamento de Historia y Ciencias Sociales, sus líneas de investigación se han centrado en el siglo XIX mexicano. 
A pesar de que la globalización, a decir de Néstor García Canclini (2005), "no es un objeto de estudio claramente delimitado, ni un paradigma científico ni económico, político ni cultural, que pueda postularse como modelo único de desarrollo" (13), ha provocado transformaciones en todos los órdenes, desde la forma distinta de entender el mundo que manifiestan las nuevas generaciones en todas sus acciones cotidianas, hasta los esfuerzos de adaptación que tenemos que hacer quienes nacimos antes de la era de Internet para no quedarnos atrás en medio de los avances tecnológicos que cambian a una velocidad vertiginosa.

El presente trabajo es un intento de comprender lo que está sucediendo desde el punto de vista de lo que implica vivir hoy en la "aldea global". Asimismo, se trata de una reflexión sobre la enseñanza de la historia en un mundo cada vez más complejo y cambiante.

\section{EL CONOCIMIENTO}

En el siglo XXI hay muchas cosas que se han transformado respecto al entorno en el que nos tocó crecer. Hasta hace unos cuantos años, el uso de las computadoras estaba restringido, no existía Internet y no teníamos el acceso al conocimiento que caracteriza a nuestro mundo actual. Por poner un ejemplo respecto a la enseñanza de la historia en esta época, si se introduce el tema en el buscador Google, existen aproximadamente siete millones y medio de sitios que contienen información al respecto. ¿Qué hacer frente a ese cúmulo de datos?, ¿cómo saber cuáles son valiosos y cuáles debemos descartar por su falta de rigor científico?, ¿cómo acceder al conocimiento que aparentemente está al alcance de cualquiera y que sin embargo, se esconde en un mar de información caótica y la mayoría de las veces contradictoria? Ese exceso de información en el que estamos inmersos hace que sea difícil discriminar y decidir qué es lo que verdaderamente vale la pena.

Por otra parte, si bien las relaciones comerciales y los medios de comunicación nos han acercado y hoy podemos consumir productos de cualquier parte del mundo o saber lo que pasa en el más recóndito rincón del planeta con sólo encender la televisión o entrar a un buscador de Internet, la mayor parte de la humanidad, sin embargo, ha quedado al margen de los adelantos tecnológicos, y a pesar de que aparentemente la información está disponible para cualquiera, en un entorno de enormes desigualdades pocos son los que pueden tener pleno acceso al conocimiento. Por ello, es pertinente reflexionar sobre lo que significa enseñar historia en los albores del siglo XXI, con las contradicciones que caracterizan a nuestra época. 
No es fácil definir las características particulares de lo que Mario Vargas Llosa (2009) ha llamado "La civilización del espectáculo", es decir, un mundo que a partir de la Segunda Guerra Mundial, después de las privaciones y la escasez vividas durante la primera mitad del siglo XX, se fue deslizando cada vez más hacia un desarrollo económico que propició el crecimiento de las clases medias, así como las posibilidades de movilidad social y ello fue un estímulo para la proliferación de la industria del entretenimiento. Así, la diversión, el huir del aburrimiento y evitar las preocupaciones y todo aquello que pudiera perturbar o angustiar, se convirtió en un mandato generacional. (14-15)

Por ello es difícil referirse a la enseñanza de cualquier disciplina en un tiempo que se caracteriza por su inmediatez. En ese sentido, la democratización de la cultura surgió como un fenómeno positivo que pretendía que ésta dejara de ser patrimonio de una élite y buscó ponerla al alcance de todos, mediante la educación y la promoción de las artes, las letras y todas las manifestaciones culturales, sólo que tuvo el efecto de trivializar la vida cultural y cambiar la calidad por la cantidad. De esa manera, la cultura comenzó a definirse como todas las expresiones de la vida de una comunidad: su lengua, sus creencias, sus usos y costumbres, su indumentaria y todo lo que en ella se practica, lo que la uniforma e iguala, y dicho concepto dejó de referirse a lo que se ha denominado "alta cultura". Ello, a decir de Vargas Llosa (2009), acabó por convertirse en "una manera divertida de pasar el tiempo, al extremo de que una ópera de Wagner, la filosofía de Kant, un concierto de los Rolling Stones y una función del Cirque du Soleil se volvieron equivalentes". (15)

En ese sentido, la ausencia de la crítica y la proliferación de lo que se ha definido como literatura light, cine light y arte light ha hecho creer al espectador que se puede ser culto, revolucionario y moderno con un mínimo esfuerzo intelectual. Así, la cultura actual, según el escritor peruano, propaga el conformismo a través de la complacencia y la autosatisfacción. De esa manera, los profesores, los pensadores y los teólogos han sido sustituidos por estrellas televisivas que ejercen gran influencia sobre las costumbres, los gustos y las modas. Ello ha tenido como consecuencia una ausencia total de crítica que ha sido llenada por la publicidad; así, ésta se ha convertido en vector determinante de la vida cultural en una sociedad que al sustituir las ideas por las imágenes, ha "relegado al desván de las cosas pasadas el ejercicio de pensar". (15-16)

Desde un punto de vista distinto, como un intento de comprender los cambios que se han sucedido en los últimos años, Alessandro Baricco (2008) intenta una explicación del universo de los protagonistas de dichas transfor- 
maciones. En su ensayo titulado "Los bárbaros", Baricco afirma que las generaciones que nacieron con Internet y que saben manejar la computadora desde sus primeros años, son mutantes que representan un cambio para la humanidad a la manera de las invasiones bárbaras de otros tiempos. Así, en realidad lo que está ocurriendo es que ellos tienen distintos códigos y se aproximan al conocimiento de formas que nosotros no comprendemos.

Según la tesis de Baricco (2008), los bárbaros son animales que quieren sobrevivir y buscan el mejor hábitat para conseguirlo. Para ellos lo importante es encontrar el sentido a lo que pasa, adquirir experiencia mediante los sistemas de paso, es decir, a través de la idea de que la intensidad del mundo no se da en el subsuelo de las cosas, sino en una secuencia dibujada "en la superficie de lo existente". (155) Así, para estos mutantes el pasado ya quedó atrás; es un "vertedero de ruinas" que sólo sirve en la medida que pueden extraer de él lo que es útil. Transforman las esquirlas del pasado en sistemas de paso que se integran al presente. (169-170)

La pregunta, entonces, es cómo crear lazos de comunicación con los protagonistas de los cambios mencionados, por un lado inmersos en el mundo del espectáculo, en el consumismo y la superficialidad, y por otro con una gran capacidad de búsqueda de información, una enorme curiosidad y al mismo tiempo una carencia de interés en cualquier cosa que no sea la forma más rápida y fácil de conseguir algo. ¿Cómo enseñar historia a estas nuevas generaciones?

\section{LA HISTORIA SE TRANSFORMA}

La definición de lo que es la historia, también se ha transformado a lo largo del tiempo. A decir de un historiador decimonónico, "sin la historia nada se sabría de cuanto ha sucedido y se ha inventado desde que existe el mundo, y ni los pueblos ni los particulares tendrían regla segura que los guiase en el curso de la vida". Es decir, la enseñanza de la historia, desde ese punto de vista, sería esencial para comprender el pasado y el presente. Además, al mostrar "los procedimientos por medio de los cuales ha ido mejorando o empeorando la condición humana" podría dar elementos para explicar las desgracias del hombre y su incapacidad para salir del "estado de infelicidad" característico de la vida política y social de los pueblos. (Larrainzar, 1992: 144)

Así, tradicionalmente se ha visto a la historia como "maestra de la vida", como faro que ilumina el camino y permite al ser humano vivir de una mejor manera gracias a la sabiduría adquirida mediante su conocimiento y su estudio. Esa idea es heredera de la creencia prevaleciente en el siglo XIX sobre las sociedades 
humanas que evolucionaban como organismos vivos, crecían en una dirección definida y estaban regidas por leyes que podían trazarse con precisión mediante la observación y la razón (Berlin, 2000: 37-38). La fe en el progreso fue la piedra angular del siglo XIX.

Sin embargo, esas creencias, a decir de Isaiah Berlin (2000), fueron sacudidas bruscamente por lo ocurrido en las primeras décadas del siglo XX, cuando fue claro que la "evolución" histórica de la humanidad quedó rota por el ascenso al poder de personajes como Adolfo Hitler y José Stalin. Así, los seres humanos y sus instituciones resultaron ser mucho más maleables, mucho menos resistentes de lo que se había pensado. Se habló entonces de un regreso a la barbarie que se había creído superada para siempre y comenzó a buscarse el retorno a una edad de oro, lo que sería imposible, dado que para volver al pasado tendrían que reproducirse las condiciones exactas en las que éste se había dado. (38) Por lo demás, la idea de que todo tiempo pasado fue mejor no deja de ser una utopía a la que se recurre en épocas difíciles, tanto personales como de una sociedad o una época.

Por otra parte, los historiadores desistieron de buscar las generalidades que supuestamente caracterizaban a las sociedades humanas. Las lecciones del siglo XX dejaron en claro que el propósito de la historia ya no sería la búsqueda de las características compartidas para explicar fenómenos específicos; quien emprendiera un análisis histórico, en cambio, tendría que encargarse de destacar lo particular y único de los diversos acontecimientos o circunstancias. Así, los estudiosos de la historia comenzaron a interesarse "en pintar un retrato que represent[ara] un modelo singular de experiencia, y no una radiografía que fuera capaz de operar como un símbolo general para todas las estructuras de un mismo tipo". (54) La paradoja, en este caso, es que en una época globalizada el hombre ha sentido la necesidad de singularizarse, de buscar lo que lo hace único en medio de la masificación y la aparente desaparición de referentes culturales.

Cuando ha transcurrido casi una década del tercer milenio, vivimos una época en que la historia, es decir, el proceso de cambio en la vida humana y en la sociedad, así como el impacto de las personas en el entorno global, se ha acelerado vertiginosamente. La velocidad en la que se suceden los hechos en la actualidad amenaza, a decir de Eric Hobsbawm (2007), el futuro de la raza humana y del planeta. Esos cambios comenzaron a mediados del siglo XX cuando terminó la historia como se había conocido desde la invención de la agricultura sedentaria. Y el problema es que la humanidad no sabe hacia dónde se dirige (19-20).

En esta etapa del desarrollo histórico de la humanidad, tan compleja, la contribución de los historiadores para comprender la situación del mundo debe ser, además de recordar lo que otros han olvidado o desean olvidar, alejarse "de la crónica de lo contemporáneo y encuadrarla en un contexto más amplio y con mayor perspectiva2 (viii), tal como lo exigen las circunstancias actuales. 
Por lo que toca a la enseñanza en nuestros días, se ha dicho que en el mundo globalizado del siglo XXI las fronteras culturales desaparecen y las concepciones sobre el tiempo y la historia son iguales en todas partes. De esa manera, a decir de Andrea Sánchez (2006), se ubica a los seres humanos "dentro de un tiempo sin duración, un espacio sin identidad y una historia sin sujetos, sin el reconocimiento real de las homogeneidades o diferencias culturales". (24) En ese sentido, cuando he cuestionado a los alumnos sobre su identidad como miembros de una determinada nación, pocos son los que han reconocido los elementos que los identifican. La mayoría no logran describir qué los une o los distingue como pertenecientes a una comunidad humana.

Es decir, por el individualismo que caracteriza a nuestra época no sólo no existen rasgos de identificación, sino que también ha desaparecido el orgullo - tan característico de la primera mitad del siglo pasado, fruto del nacionalismo imperante entonces - por pertenecer a un país determinado. A ello ha contribuido el debilitamiento del Estado que ha provocado que la lealtad que le profesaban antaño los ciudadanos haya desaparecido. De ahí que el respeto por la ley haya disminuido y que en esta época sólo se acaten aquellas leyes que se considera tienen una justificación moral, es decir, que poseen legitimidad. Si a ello se añade que la globalización ha traído consigo un enorme aumento de la movilidad y la eliminación de controles efectivos en las fronteras, entonces cada vez es más difícil controlar lo que ingresa a un país, tanto objetos materiales como ideas (Hobsbawm, 2007: 161-162). Así, en una realidad en la que las fronteras se desvanecen, el éxito económico se equipara con la felicidad y se busca la gratificación inmediata, la comprensión del pasado queda como una asignatura obsoleta que no tiene sentido en un mundo acostumbrado a la inmediatez.

Por otra parte, una paradoja de nuestro tiempo es que la pretendida homogeneidad cultural de los Estados-nación modernos esconde en realidad tensiones y conflictos sociales derivados de la falta de reconocimiento de las diferencias de las minorías étnicas que no se adaptan al modelo impuesto por los estados monoétnicos. Ello ha provocado el resurgimiento de la intolerancia hacia quienes son distintos de la mayoría, y ha derivado en la falta de comprensión entre los miembros de un mismo grupo que, sin embargo, se saben distintos (Stavenhagen, 1996: 262). Es curioso, a decir de Néstor García Canclini (2005), que la "disputa de todos contra todos, en la que van quebrando fábricas, se destrozan empleos y aumentan las migraciones masivas y los enfrentamientos interétnicos y regionales, sea llamada globalización". (10) 
Así, el mayor reto al que se enfrenta quien enseña historia en estos tiempos es lograr que los estudiantes - muchos de ellos convencidos de que el conocimiento es sólo un medio y no un fin en sí mismo - se interesen por temas que en la época actual pueden ser calificados como aburridos, poco interesantes e inútiles. Sin embargo, los seres humanos somos tiempo. El pasado está en nosotros, nos explica y define. De ahí que la comprensión de la historia sea fundamental para entender, también, nuestra vida y los significados de la forma en que nos movemos y somos.

Porque, a decir de Eric Hobsbawm (2002: 38) la posición que ocupamos respecto al pasado y las relaciones que existen entre éste, el presente y el futuro no son sólo de vital interés para nosotros, sino que son imprescindibles. Por ello en nuestra vida recurrimos constantemente al pasado en formas tan cotidianas como los álbumes de fotos o videos de acontecimientos especiales como bodas, cumpleaños y demás eventos familiares.

Por otra parte, a decir de Peter Burke (2000), para muchas personas es cada vez más necesario renovar sus vínculos con el pasado, especialmente el de su propia comunidad, su familia, su ciudad, su lugar de origen, su grupo étnico o religioso, como una manera de orientarse en un periodo de cambios sociales cada vez más rápidos. (30) En el caso de la enseñanza de la historia, ésta se vuelve imprescindible cuando se trata de comprender cabalmente la propia realidad tanto como la ajena.

MI EXPERIENCIA

En este universo globalizado y sumamente complejo que se ha tratado de describir en unas cuantas líneas, y por lo aparentemente banal que pueda ser el estudio de la historia para las nuevas generaciones, es un reto enseñar esa disciplina a "los bárbaros" mencionados por Alessandro Baricco (2008). No obstante, mi experiencia en ese sentido ha sido sumamente enriquecedora. Una de las estrategias más útiles para enseñar historia a jóvenes extranjeros es la imagen. En un mundo en el cual ésta es un recurso imprescindible, su uso me ha ayudado a hacer más comprensibles para los estudiantes los lugares, los personajes y situaciones de la vida cotidiana gracias al análisis de retratos, de cuadros de paisajes y de sitios específicos. Por supuesto, la comparación también es un arma de comprensión intercultural. Así, les pido que hagan comparaciones entre su cultura y la mexicana para que puedan explicarse lo que ven. Finalmente, tienen que elaborar un ensayo en el cual expresen lo que piensan de México y de su experiencia en este país a partir de lo aprendido en las sesiones de clase. 
La mayoría de los estudiantes han coincidido en lo mucho que el curso de historia les ayuda para comprender mejor la realidad a la que se enfrentan. Han mencionado su mayor entendimiento de las desigualdades que son patentes en el país, de los conflictos políticos y sociales, pero también han destacado rasgos positivos como la alegría y la calidez de los habitantes de México, su gusto por la fiesta y su flexibilidad. Por poner un ejemplo de las opiniones sobre nuestro país, una estudiante rusa comentó en su ensayo lo mucho que le llamaba la atención el hecho de que los mexicanos no dijeran claramente lo que querían, y destacó nuestra tendencia a decir frases ambiguas como "nos vemos un día de estos", "te llamo en la semana", "al ratito llego". Para una estudiante japonesa, en cambio, esa ambigüedad en la forma de expresarse de los mexicanos es una característica que se parece a la manera de ser de los japoneses, que "no dicen realmente lo que piensan". Para otra alumna vietnamita, su viaje y su estancia en México fue de lo mejor que le ha pasado en la vida.

El análisis de lecturas que hablan de la historia mexicana desde el punto de vista de especialistas en la materia también ha sido motivo de reflexión para los estudiantes. Muchos de ellos comparan lo sucedido en México con lo ocurrido en la misma época en sus propios países. Para otros, al conocer las características del pasado mexicano han podido entender mejor la forma en que vivimos actualmente.

Por lo demás, la experiencia en el salón de clase no sólo es enriquecedora para los alumnos. Los maestros aprendemos mucho de ellos, no sólo de sus propias costumbres, sino de nosotros mismos, ya que al no estar inmersos en nuestra realidad, al mirar con ojos nuevos las cosas que nosotros ya no vemos por la fuerza de la costumbre, nos ayudan a vernos de nuevo. Así, las interpretaciones que sobre la historia ha hecho quien esto escribe, se han alimentado o han cambiado con los aportes de los estudiantes extranjeros.

\section{CONSIDERACIONES FINALES}

Para terminar, cabe hacer la reflexión sobre lo que el concepto de globalización ha significado en la enseñanza de la historia en la época actual. Es un hecho que el mundo se ha vuelto pequeño, que las distancias son menores y que aparentemente tenemos más acceso al conocimiento de culturas distintas a la nuestra. También es cierto que ello ha contribuido a que las características de las diferentes culturas sean menos evidentes, y que en ocasiones parezca que no existen.

Esos cambios que se han sucedido de manera vertiginosa en los últimos años, y que han contribuido a que las diferencias entre generaciones sean mayores, también han llevado a ahondar la falta de entendimiento entre los jóvenes que 
han crecido inmersos en el mundo tecnológico y global del siglo XXI y quienes nacimos en el siglo pasado. En ese sentido, la gran muralla china, el símbolo que Baricco utiliza para ilustrar la forma de defensa a la que recurrió la cultura china frente a lo que le era ajeno, se convierte en un símil de la frontera entre los bárbaros y nosotros. Y eso no ha sucedido sólo en esta época, sino cada vez que la humanidad ha sido testigo de una transformación tan grande como la que estamos viviendo.

En ese aspecto, la historia es el puente que nos puede ayudar a trascender esas diferencias, a dejar de ver con miedo a aquellos que nos parecen distintos y volvernos, así, más tolerantes. Se puede decir que si algo bueno ha traído la idea de la globalización es la aceptación de los otros y la tolerancia hacia los diferentes, hasta encontrar en ellos los puntos de referencia que nos ayuden a entenderlos y entendernos, a transformar y transformarnos con el intercambio de conocimientos y experiencias.

En conclusión, me parece pertinente unas frases de Baricco (Baricco, 2008: 212) que pueden resumir hacia dónde debemos caminar para tender puentes entre los diferentes, para que logremos alimentarnos mutuamente:

[...] se trata de ser capaces de decidir qué hay, en el mundo antiguo, que queramos llevarnos hasta el mundo nuevo. Qué queremos que se mantenga intacto incluso en la incertidumbre de un viaje oscuro. Los lazos que no queremos romper, las raíces que no queremos perder, las palabras que queremos seguir pronunciando y las ideas que no queremos dejar de pensar. Es un trabajo refinado. Un tratamiento. En la gran corriente, poner a salvo todo lo que apreciamos. Es un gesto difícil porque no significa, en ningún caso, ponerlo a salvo de la mutación, sino, en todo caso, dentro de la mutación. Porque todo lo que se salve no será de ninguna manera lo que mantuvimos a salvo del tiempo, sino lo que dejamos que mutara, para que se transformara él mismo en un tiempo nuevo. 
BibLIOGRAFÍA

BERLIN, I. (2000) El sentido de la realidad. Sobre las ideas y su historia. Madrid:Taurus. (Pensamiento).

Burke, P. (2000) Historia y teoría social. México: Instituto Mora. (Colec. Itinerarios). García CanclinI, N. (2005) La globalización imaginada. Argentina: Paidós.

Hobsbawm, E. (2007) Guerra y paz en el siglo XXI. Barcelona: Crítica. (Memoria Crítica). , (2002) Sobre la historia. Barcelona: Crítica. (Biblioteca de Bolsillo, 87).

LaRRAINZAR, M. (1992) Algunas ideas sobre la historia y manera de escribir la de México, especialmente la contemporánea, desde la declaración de independencia, en 1821, hasta nuestros días. en Ortega y Medina, J. Polémicas y ensayos mexicanos en torno a la historia. México: UNAM, Instituto de Investigaciones Históricas, pp. 133-255. (Serie Documental, 8).

Sánchez Quintanar, A. (2006) Reflexiones sobre la historia que se enseña, en Galván Lafarga, L. (coord.), La formación de una conciencia histórica. Enseñanza de la historia en México, México: Academia Mexicana de la Historia. pp. 19-45.

Stavenhager, R. (1996) La educación para un mundo multicultural, en Delors J. et al. La educación encierra un tesoro. México: Dower, UNESCO, pp. 261-266. (Colec. Educación y cultura para el nuevo milenio).

VArgas Llosa, M. (2009) La civilización del espectáculo. Letras Libres, XI, (122). México, pp. 14-22. 